\title{
Male Contraceptive Behavior in Rajshahi District of Bangladesh.
}

Mosiur R, Rafiqul I and Matin A

Department of Population Science and Human Resource Development, University of Rajshahi, Bangladesh.

\begin{abstract}
This article examines the actual scenario of male involvement either as a user of contraceptive methods or supportive reproductive partners of women on contraceptive use in Rajshahi district of Bangladesh. The analysis shows that, knowledge and use of contraception are low in our study area. Comparative figures of contraceptive practice between men and women found a large disparity. Findings reveal that the user rate of all male contraceptive methods (e.g., condom at 17 percent) is still low compared to that of female methods (pill at 33.8 percent), which shows that men like to impose contra ceptive responsibility on women. Identification of socio-economic and demographic differentials affecting contraceptive behavior of men is performed through the technique of logistic regression. This paper elucidates that education, residence, fertility preference, mass media facility and knowledge about AIDS are the significant factors to influence contraceptive practices among men. Regarding the factors shunning the contraceptive practice we found that men's opposition to use contraceptive methods is as most significant. The next reason for not using is related to contraceptive method.
\end{abstract}

KEY WORDS: Modern Method, Traditional Method, Fertility, AIDS/STDS

\section{INTRODUCTION}

Concern over the rising population of Bangladesh has been received due attention by different organizations working in the field of population control and its effective management from early sixty's of the last century. 1 Various family planning programs are developed to make significant contribution in this field. Interestingly, most of these programs are designed for female and promote female methods to achieve the demographic and target oriented objectives with little emphasis on equality issue. Equality is interpreted as the shared responsibility of men and women. In the past, men have not shared equal responsibility for fertility regulation, specifically, on contraceptive use. 2 Consequently, the role of men as important decision maker in the process of reproduction has not been much investigated. To bring more dynamism on reproductive health programs, the issue of male involvement is getting much importance today. In our paper we like to illustrate here the actual scenario of male involvement on contraceptive use in Rajshahi district of Bangladesh.

Correspondence author

Md. Mosiur Rahman

Lecturer

Department of Population Science and Human

Resource Development

University of Rajshahi,

Rajshahi-6205, Bangladesh.

E-mail: swaponru_2000@yahoo.com

\section{MATERIALS AND METHODS}

The data were collected from a field survey conducted in the district of Rajshahi of Bangladesh. The data were collected from both rural and urban areas of Rajshahi district. Information was collected of 500 married male household heads (male aged 15-64 years; as they are more responsive about the involvement in reproductive health) by interview method. Respondents were selected by purposive sampling method. For rural areas we had selected three villages under Horogram Union of Paba and for urban areas we selected Rajpara Thana of Rajshahi Metropolitan City Corporation. Data analytic methods envisaged in this paper are percentage distribution, graphical representation and logistic regression analysis.

\section{RESULTS}

Before going directly into the findings concerning male contraceptive behavior, it is appropriate to examine male's knowledge about various methods of contraception. Overall contraception knowledge of men was found to be high. If we look at Table I we observe that among all methods, pill and condom are the widely known methods by men. 
Table I. Percentage distribution of contraceptive knowledge reported by respondents

\section{Contraceptive method}

\section{Any modern method}

Pill

\section{Percentage}

IUD*

\section{Injectable}

Condom

\section{Female sterilization}

Male sterilization

\section{Any traditional method}

\section{Safe time}

Withdrawal

95.2

19.2

67.2

95.2

88

54.6

*IUD is intrauterine device

Among all modern methods, IUD is the method where men's perception is lowest being only 19.2 percent (Figure 1).

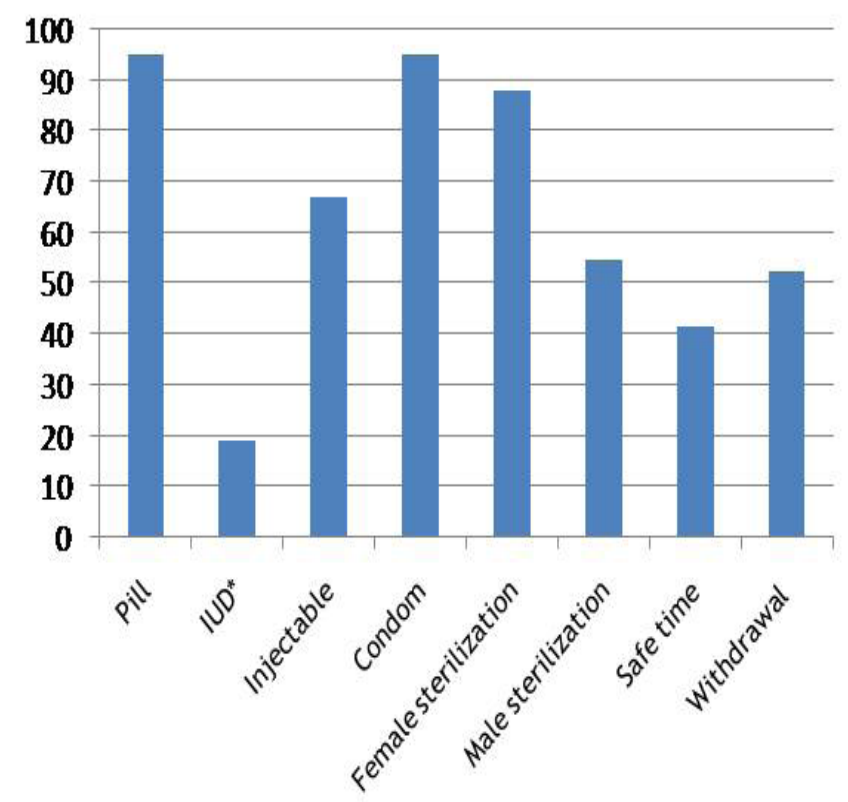

Figure 1. Men's knowledge about contraceptive methods

Table II presents the percentage distribution of men using contraception at the time of the interview according to the method they used.
Table II. Men's contraceptive practice in the study area

\begin{tabular}{ll} 
Contraceptive method & Percent \\
\hline Modern methods & $51.8(259)$ \\
Pill & $33.8(169)$ \\
Condom & $17.0(85)$ \\
Male sterilization & $1.0(5)$ \\
Traditional methods & $3.2(16)$ \\
Safe time & $1.0(5)$ \\
Withdrawal & $1.2(6)$ \\
Other & $1.0(5)$ \\
No contraception & $45.0(225)$
\end{tabular}

According to this table 51.8 percent men used modern methods and an additional 3.2 percent used traditional methods, for a total of 55.0 percent of men using contraceptive methods. The pill was the most popular method for men in our study area (33.8 percent) followed by condom (17.0 percent).

We have also computed contraceptive prevalence (the percentage of all married men and women currently using some type of contraception. Place of residence shows strong urban-rural differential on the involvement of men in current use of contraception. 
Table III. Percentage distribution of men and women of currently using contraceptive methods by selected background variables.

\begin{tabular}{|c|c|}
\hline Characteristics & $\begin{array}{l}\text { Percentage } \\
\text { Yes }\end{array}$ \\
\hline \multicolumn{2}{|l|}{ Place of residence } \\
\hline Urban & 58.8 \\
\hline Rural & 51.2 \\
\hline \multicolumn{2}{|l|}{ Religion } \\
\hline Muslim & 55.4 \\
\hline Others & 50 \\
\hline \multicolumn{2}{|l|}{ Respondent's education } \\
\hline Illiterate & 46.8 \\
\hline Primary incomplete & 41.8 \\
\hline Primary complete & 71.4 \\
\hline Secondary and higher & 69.1 \\
\hline \multicolumn{2}{|l|}{ Wife's education } \\
\hline Illiterate & 46.6 \\
\hline Primary incomplete & 41.4 \\
\hline Primary complete & 69.5 \\
\hline Secondary and higher & 72.4 \\
\hline \multicolumn{2}{|l|}{ Occupation } \\
\hline Non-manual & 62.6 \\
\hline Manual & 48.5 \\
\hline \multicolumn{2}{|l|}{ Watching T V } \\
\hline Yes & 57.5 \\
\hline No & 49 \\
\hline \multicolumn{2}{|c|}{ Respondent's age at marriage } \\
\hline$<20$ & 54.7 \\
\hline $20-25$ & 51.6 \\
\hline $25-30$ & 56.8 \\
\hline $30+$ & 78.9 \\
\hline \multicolumn{2}{|l|}{ Current age } \\
\hline$<25$ & 46.7 \\
\hline 25-34 & 70.9 \\
\hline $35-49$ & 56.8 \\
\hline $50+$ & 15.2 \\
\hline \multicolumn{2}{|c|}{ Respondent's age at last child } \\
\hline$<20$ & 78.3 \\
\hline $20-25$ & 74 \\
\hline $25-30$ & 66 \\
\hline $30+$ & 44.9 \\
\hline \multicolumn{2}{|l|}{ Children ever born } \\
\hline None & 46.4 \\
\hline 2-Jan & 70.7 \\
\hline 4-Mar & 45 \\
\hline 4+ & 18.5 \\
\hline \multicolumn{2}{|l|}{ Children Surviving } \\
\hline None & 46.4 \\
\hline 2-Jan & 68.1 \\
\hline 4-Mar & 39.4 \\
\hline $4+$ & 19.2 \\
\hline
\end{tabular}

Table III shows that the current use of contraception is substantially higher in urban areas than rural population. Table III also had shown that ...... Muslim couples were using contraceptive methods (about 55.4 percent) compared with non-Muslim couples (50.0 percent). Respondents with lower education were found to use less contraception. The percentage was higher if the respondents received secondary or higher education.

About 62.6 percent respondents who were non-manual workers (Serviceman, business man etc.) consequently higher users of contraceptive methods as compared manual workers (Day labors, farmers etc). Regarding mass media exposure respondents who watched television at least four times within a week were using contraceptive methods more with their partners as against the respondents who did not watch television at all. Respondent's age at marriage is an important factor for using contraceptive methods as he/they mature or not according to their own age3. Table III indicates that a vast majority of the respondents who were 30 years and above currently practicing contraceptives with their partner (70.9 percent) than the respondents belonging to other age category. It is also observed those respondents who have/or 2 children

Table IV. Percentage distribution of reasons for not using contraceptive methods reported by respondents

\begin{tabular}{ll}
$\begin{array}{ll}\text { Reasons for not using } \\
\text { contraceptive methods }\end{array}$ & Percentage \\
\hline Fertility related reason & $11.0(55)$ \\
Wife dead & $1.2(6)$ \\
\hline Menopausal & $5.0(25)$ \\
Breastfeeding & $2.8(14)$ \\
\hline Postpartum amenorrheic & $2.0(10)$ \\
\hline Method related reason & $16.4(82)$ \\
\hline Health concerns & $8.4(42)$ \\
Fear of side effects & $3.8(19)$ \\
Expensive & $4.2(21)$ \\
Opposition to use & $17.6(88)$ \\
Partner opposed & $16.6(83)$ \\
Religious prohibition & $1.0(5)$ \\
\hline Total & $45.0(225)$
\end{tabular}

were more users of contraceptive methods (70.7 percent and 68.1 percent).

A significant number of men were not using contraception in our survey. The reasons observed can be placed into three major groups methods in Table IV namely: fertility related reasons, opposition to use contraception and lastly due to factors affecting specific methods of contraception.

Respondent's attitudes towards contraceptive methods are expressed in the group like opposition to use. The opposition comes from either partner's behavior or due to religious culture was due to their partner 
wanted more children. 17.6 percent respondents showed their unwillingness to use contraceptives methods, 16.6 percent of the respondent's opposition to contraceptive usage. Religious reason was seen only $1 \%$ of the respondents. We also found in study that 8.4 percent respondents refrained from practicing contraceptive methods because of health concerns. 3.8 percent because of fear of side effects and the remaining 4.2 percent mentioned cost is a factor.

Table V. Logistic regression to explain contraceptive practices of men

\begin{tabular}{|c|c|c|}
\hline \multirow[t]{2}{*}{ Independent variable } & \multicolumn{2}{|c|}{$\begin{array}{l}\text { Dependent variable : Current use of } \\
\text { male contraceptive method }\end{array}$} \\
\hline & Coefficient (b) & Odds ratio Exp (b) \\
\hline \multicolumn{3}{|l|}{ Education of Husband } \\
\hline No education (Ref.) & ... & 1 \\
\hline Primary Incomplete & 0.007 & 1.007 \\
\hline Primary Complete & 0.456 & $1.578 *$ \\
\hline Secondary \& Higher & 0.531 & $1.701^{*}$ \\
\hline \multicolumn{3}{|l|}{ Place of Residence } \\
\hline Rural (Ref) & $\ldots$ & 1 \\
\hline Urban & 0.105 & $1.111^{*}$ \\
\hline \multicolumn{3}{|l|}{ Occupation } \\
\hline Manual (Ref) & $\ldots$ & 1 \\
\hline Skilled & 0.005 & $1.005^{*}$ \\
\hline \multicolumn{3}{|l|}{ Mass Media } \\
\hline No access (Ref) & $\ldots$ & 1 \\
\hline Yes & 0.566 & $1.762^{*}$ \\
\hline \multicolumn{3}{|l|}{ Knowledge of AIDS } \\
\hline No (Ref) & $\ldots$ & 1 \\
\hline Yes & 1.924 & $6.846^{-3 *}$ \\
\hline \multicolumn{3}{|l|}{ Fertility Preference } \\
\hline Want More (Ref) & ... & 1 \\
\hline No More & 0.392 & $1.480^{\circ}$ \\
\hline \multicolumn{3}{|c|}{$\begin{array}{l}\text { Sexually Transmitted Disease } \\
\text { (Knowledge) }\end{array}$} \\
\hline No (Ref) & ... & 1 \\
\hline Yes & 0.151 & 1.163 \\
\hline Constant & -4.1633 & 0.016 \\
\hline
\end{tabular}

(Ref)=Reference category, Here ${ }^{* * *},{ }^{* *}$ and * indicates $p<0.001$ (highly significant), $p<0.01$ (significant), and $\mathrm{p}<0.05$ (less significant).

Table $\mathrm{V}$ shows the factors associated with the determinants of current contraceptive use by men among the study population. Six variables were found to significantly influence the use of contraception by males. The analysis indicates that as the level of education increases contraceptive practice among men also rises. Respondents having secondary and higher education were 1.701 times more likely to prefer male contraceptive practice of male methods as compared to those respondents who have no education. Contraceptive practices by male was significantly higher $(p<0.01)$ in urban areas than in rural areas. The table also elucidates that respondents whose professions were skilled (Service, business etc.,) are more likely to prefer male contraceptive methods as compared to manual (Day labor, farmer etc. In our model we find that respondents who have access to mass media fare 1.762 times more probable to use contracep- tive methods than men who do not have access. Contraceptive practice by men who have knowledge of AIDS is nearly seven times higher than those who lack knowledge. Fertility preference of men also influences the decision regarding contraceptive use. Usually men who have many children prefer to limit having anymore4. Our study also confirmed their observation knowledge of STD among men also influence their decision regarding contraceptive use. 5 Men who were knowledgeable of STD are 1.163 times more likely to use contraceptive methods. 


\section{DISCUSSION}

The analysis shows that knowledge and use of contraception is low in our study. $55 \%$ of men were using some method and we also found that knowledge about modern methods of contraceptive among males relatively high but interestingly knowledge about traditional methods is lower. The comparative figures of contraceptive practice among men and women showed a large disparity, practice among women was twice that of men (33.8 percent of respondents wife used the OCP pill method where as only 17 percent respondents used condom). Significant differences were noted in contraceptive practice between the modern and rural respondents. Rural-urban differentials affecting contraceptive use was also visible. Opposition to the concept of contraceptive was one of the main factors for men refraining for the practice. The other reason was due to factors related to the method of contraception itself.

Among the factors determining contraceptive use among men, education appears to be the most significant one. The place of residence, occupation of respondents, access to mass media, respondent's knowledge about AIDs and fertility preference also appear to be significant factors determining the level of contraception use among the men. It is our opinion this study shows that the practice of contraception among men is not satisfactory. Much work has to be done to address this issue to attain success in controlling the population of our country. In the light of the above discussions some policy implications have been recommended:

(i) Contraceptive methods among men is very low (e.g., condom 17 percent). For this purpose, governments, nongovernmental organizations (NGOs), donors' agencies and relevant stakeholders should ensure availability, accessibility and sustained advocacy for use of condom for dual protection against unwanted pregnancy and STIs/HIV (ii) Educating men about the economic benefits of family planning might be more effective than attempting to persuade them to accompany women to family planning consultations purely on the basis of their responsibility as husbands and partners (iii) The mass media should be used more frequently and more effectively (iv) more importantly confusion and fear among men about the modern methods should be removed, (v) help men to communicate with their partners and make contraceptive choices together.

\section{REFERENCES}

1. Mitra SN, Lerman C, Islam S. Bangladesh Contraceptive Survey -1991: Final report. Dhaka: Mitra and Associates, 1993.

2. KHANA. Integrating Care and Support into HIV/AIDS Prevention Projects. Report on Participatory Project Reviews and Re-Design Conducted by KHANA Partner NGOs in 2000. 2000

3. Hossain SMM, Duffield A, Taylor A. An evaluation of the impact of a US\$60 million nutrition programme in Bangladesh. Health Policy Plan 2005; 20:35-40

4. Ross J, Mauldin WP, Miller VC. Family planning and population: A compendium of international statistics. New York: The Population Council, 1993.

5. Ross J, Stover J, Willard A. Profiles for family planning and reproductive health programs (116 countries). New York: The Futures Group International, 1999. 
